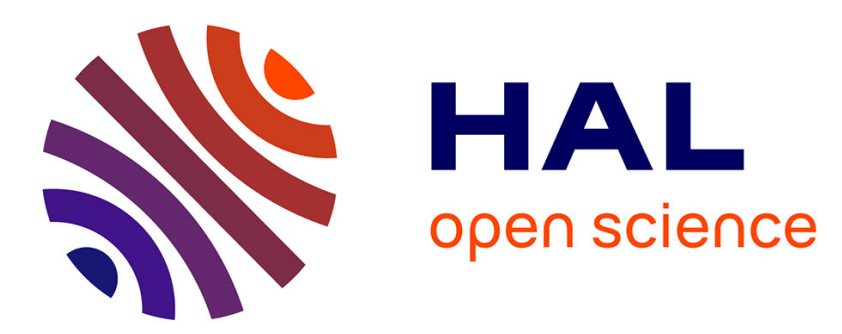

\title{
Technical refolding of proteins: Do we have freedom to operate?
}

\author{
Maria Eiberle, Alois Jungbauer
}

\section{To cite this version:}

Maria Eiberle, Alois Jungbauer. Technical refolding of proteins: Do we have freedom to operate? Biotechnology Journal, 2010, 5 (6), pp.547. 10.1002/biot.201000001 . hal-00552343

\section{HAL Id: hal-00552343 \\ https://hal.science/hal-00552343}

Submitted on 6 Jan 2011

HAL is a multi-disciplinary open access archive for the deposit and dissemination of scientific research documents, whether they are published or not. The documents may come from teaching and research institutions in France or abroad, or from public or private research centers.
L'archive ouverte pluridisciplinaire HAL, est destinée au dépôt et à la diffusion de documents scientifiques de niveau recherche, publiés ou non, émanant des établissements d'enseignement et de recherche français ou étrangers, des laboratoires publics ou privés. 


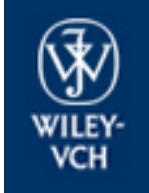

Biotechnology Journal

\section{Technical refolding of proteins: Do we have freedom to operate?}

\begin{tabular}{|c|c|}
\hline Journal: & Biotechnology Journal \\
\hline Manuscript ID: & biot.201000001.R1 \\
\hline Wiley - Manuscript type: & Review \\
\hline $\begin{array}{r}\text { Date Submitted by the } \\
\text { Author: }\end{array}$ & 30-Mar-2010 \\
\hline Complete List of Authors: & $\begin{array}{l}\text { Eiberle, Maria; Boehringer Ingelheim RCV } \\
\text { Jungbauer, Alois; University of Natural Resources and Applied Life } \\
\text { Sciences, Department of Biotechnology }\end{array}$ \\
\hline Primary Keywords: & Biochemical Engineering \\
\hline Secondary Keywords: & Bioseparation \\
\hline Keywords: & refolding, patent, continuous \\
\hline
\end{tabular}

\section{S) ScholaroNE \\ Manuscript Central}


For submission to Biotechnology Journal Ms. No. biot.201000001

\title{
Technical Refolding of Proteins, Do we have Freedom to Operate?
}

\author{
Maria K. Eiberle ${ }^{1,3}$, Alois Jungbauer ${ }^{2 *}$ \\ ${ }^{1}$ Boehringer Ingelheim RCV \& Co GmbH, Vienna, Austria \\ ${ }^{2}$ Department of Biotechnology, University of Natural Resources and Applied Life Science, Vienna, Austria \\ 3 current address Rentschler Biotechnologie GmbH, Laupheim, Germany
}

$1^{\text {st }}$ revision

* Corresponding Author:

Mailing address: Muthgasse 18, 1190 Wien, Austria

E-mail address: alois.jungbauer@boku.ac.at

Tel.: +43 136006 6226; Fax: +4313697615 


\begin{abstract}
Expression as inclusion bodies in Escherichia coli is a widely used method for the large-scale production of therapeutic proteins, that do not require post-translational modifications. High expression yields and simple recovery steps of inclusion bodies from the host cells are attractive features in the industrial scale. However, the value of an inclusion body based process is dominated by the solubilization and refolding technologies. Scale-invariant technologies, economically and applicable for a wide range of proteins are requested by industry. The main challenge is to convert the denatured protein in its native conformation at high yields. Refolding competes with misfolding and aggregation. Thus, yield of native monomer depends strongly on the initial protein concentrations in the refolding solution. Reasonable yields are attained at low concentrations $(\leq 0.1 \mathrm{mg} / \mathrm{mL})$. However, that requires large buffer tanks and time-consuming concentration steps. We attempt to give an answer to which extent refolding of proteins is protected by patents. Low-molecular mass additives have been developed to improve refolding yields through the stabilization of the protein in the solution and shielding hydrophobic patches. Progresses were established in the field of highpressure renaturation and on-column refolding. Mixing times of the denatured protein in the refolding buffer were reduced by newly developed devices and the introduction of specific mixers. Concepts of continuous refolding were introduced in order to reduce tank sizes and increase yields. A few patents covering refolding of proteins will expire soon or have expired. This gives more freedom to operate.
\end{abstract}

Keywords: Inclusion bodies, refolding, E. coli, recombinant proteins, on column, additives 


\section{Introduction}

Approximately $40 \%$ of all biopharmaceuticals are produced in E. coli cells [1]. E. coli cells grow rapidly to high cell densities on inexpensive substrates and well established fermentation strategies are attractive for an economic expression in industrial scales. Furthermore, the genetic properties of $E$. coli are well characterized and the strains are easy to handle. This explains why E. coli is an economic and efficient production system, and widely used for the expression of recombinant proteins [2,3]. However, recombinant proteins are not always folded in their proper and active conformation during protein biosynthesis. For a broad majority of heterologous proteins, secretion in E. coli results in 0.5 to $0.8 \mathrm{~g} \mathrm{~L}^{-1}$ volumetric yield [4]. Higher titers can be attained, but usually require an extensive engineering of the fermentation protocol and expression system [5,6,7]. Thus many products on the market are produced as inclusion bodies in the cytoplasm of E. coli, where high fermentation titers can be achieved according to Biopharmaceutical Products in the US and European Markets 6th edition. Inclusion bodies contain the target protein as insoluble aggregates, present in a kind of paracrystalline form. The proteins exist in non-native conformations but with a certain content of secondary structure elements [8]. After solubilization with chaotropic buffers in a reducing environment an elaborative renaturation step is required to refold the protein in its native and active conformation [9]. Anyway, this technology is widely used. Beside high expression yields there are other benefits, that compensate the disadvantage of an additional refolding step: Inclusion bodies have a higher density $(\sim 1.3 \mathrm{~g} / \mathrm{mL})$ than other cellular components and cell debris and can be easily separated and purified by a combination of cell homogenization and centrifugation. During expression the target protein accumulates in the inclusion bodies and is mostly resistant to proteolytic attacks of cell proteases. After primary isolation of inclusion bodies adhesive impurities such as cell debris and host cell proteins can be reduced by several wash and centrifugation steps. Finally a high purity of up to $90 \%$ of the product protein can be achieved in inclusion bodies. This simplifies and reduces subsequent purification steps $[10,11]$.

The process for the production of recombinant protein from inclusion bodies comprises cell cultivation and harvest, disruption, recovery of inclusion bodies, solubilization, refolding and reoxidation of disulphide bonds and further purification steps (Figure 1) [11,12]. If inclusion bodies contain high amounts of impurities, a denatured purification step of the solubilized protein can be performed prior to refolding. Popular methods are ion exchange, size exclusion or metal ion affinity chromatography $[13,14,15]$. 
Inclusion bodies are aggregated and densely packed paracrystalline forms of protein. These refractile particles are solubilized in high concentrations of chaotropic agents such as urea or guanidine hydrochloride. Reducing conditions are inevitable, as non-native intra- and intermolecular disulfide bonds may have been formed in inclusion bodies during translation. Solubilization results in a protein in its denatured form. The subsequent step transfers the unfolded and reduced protein into conditions, where the formation of native and bioactive structures is favored. Of all process steps, refolding is the most crucial step. It decides on the efficiency of an inclusion body based process [16,17,18].

Renaturation is initiated by reducing or removing the chaotropic solvent. The yield of the refolding step depends strongly on the renaturation conditions such as $\mathrm{pH}$, redox conditions, buffer additives and protein concentrations. These conditions have been empirically optimized for each individual protein.

Most proteins contain cysteine residues that form disulfide bonds, which are required for the formation of a native, bioactive structure. For in vitro refolding it is usually essential to add a redox buffer system to support the formation of native disulfide bonds. Supplementing the refolding buffer with low molecular weight thiol reagents allows the formation of disulfide bonds, as well as the reshuffling of incorrect formed bonds. Generally a combination of a reduced and oxidized component is used, for example cysteine/cystine or reduced/oxidized glutathione. Suitable ratios must be found to maximize yields [16,19]. Molar ratios of reduced to oxidized agents are recommended between 5:1 and 1:1. These ratios provide a suitable redox potential for the formation and reshuffling of disulfide bonds [20,21].

However, the correct folding pathway competes often in disadvantage, with aggregation and misfolding of the target protein. These two reactions dominate the efficiency of the in vitro refolding step. After dilution of the unfolded and reduced protein in a refolding buffer, transient intermediates (I) are formed (Figure 2). Usually, these intermediates are partially folded and hydrophobic patches are not completely buried in the core of the protein. There are two proposed reaction pathways for these intermediates. One leads to the native conformation, where are intramolecular interactions involved. This reaction follows a kinetics of first order. The other pathway directs to aggregates where intermolecular interactions are responsible for a second- or higher-order reaction. This kinetic partitioning explains decreasing refolding yields with increasing initial concentrations of unfolded and reduced protein $[22,23,24,25]$. The decline of the refolding yield with rising concentrations of the denatured protein is demonstrated in Figure 3 for $\alpha$-lactalbumin and a single-chain antibody fragment $(\mathrm{scFv})$. The susceptibility of aggregation is here clearly higher for the scFv. At concentrations $\leq 0.1 \mathrm{mg} / \mathrm{mL}$ both proteins can be totally renatured. However, increasing the concentration of the denatured protein leads to a tremendous loss of native protein. As 
aggregation results from nonspecific interactions between hydrophobic regions or partially folded structures of different polypeptide chains, it is usually irreversible [26]. Suppressing aggregation is therefore an inevitable step to achieve high yields of native and active protein. A common process for protein refolding in industry is batch dilution at very low protein concentrations $(\leq 0.1 \mathrm{mg} / \mathrm{mL})$ [20,27]. However, this requires large volumes of refolding buffer, huge reactors and additional concentration steps. Beside high costs for timeconsuming steps, waste disposal has also to be taken into account. Therefore the refolding step needs to be carefully optimized, to gain a simple and cost-effective bioprocess [16]. As consequence, conditions have to be found, where the hydrophobic interactions are suppressed and refolding to the native protein is favored. Unwanted side reactions as misfolding and aggregation have to be decelerated. Thus a lot of research and development have been done to optimize various parameters in the refolding step. One approach is the search and development of new additives, supporting the solubility after dilution and shield hydrophobic patches during folding. Other approaches focus on the addition mode of the denatured protein to the renaturation buffer. Reduced mixing times result in lower local protein concentrations and decrease aggregation rates [10]. Refolding under high pressures or on a column matrix is also a possibility to attain high recovery rates in a renaturation process $[9,10]$.

It is not the purpose of the manuscript to give advice how to circumvent existing patents. We want to draw attention to patent literature, which may prevent the application of certain refolding procedures. Mainly we focus on process patents, less on patents expressing a certain protein a unique refolding conditions.

\section{Refolding conditions and processes}

\section{Refolding by direct dilution}

The simplest method to refold proteins is the addition of the unfolded and reduced protein directly to the refolding buffer. In biopharmaceutical manufacturing this is a widely used method, as this addition mode is cheap and easy to scale and validate, respectively. Due to the aggregation characteristics of the proteins, concentrations are kept low (usually $\leq 0.1 \mathrm{mg} / \mathrm{mL}$ ) to attain reasonable refolding yields. Higher concentrations enhance the probability of collisions of unfolded or partially folded protein and lead to higher aggregation rates. Thus working at higher concentrations demand a controlled addition of the denatured protein to the renaturation buffer. Aggregation is reduced, if low local protein concentrations are rapidly achieved in the refolding tank. Therefore, short mixing times are inevitable for an efficient process. To increase the yield of native protein, dilution can be done as fed-batch and continuous dilution. Several groups have claimed these methods but patent protection have 
been recently expired [28,29]. In a stirred tank various parameters influence the refolding yield, as the intensity of mixing, the injection rate, the injection point, the concentration of denatured protein and the total protein concentration [30,31]. For example, lysozyme shows higher refolding yields in fed-batch addition compared to simple batch dilution $[32,33]$. Another continuous solution was filed by Buus et al. in 2002 [34]. In a mixing chamber the denatured protein is mixed with the refolding buffer and the refolded protein is recovered through a connected expanded bed absorption column. A benefit is here the possibility to recycle the refolding buffer [35]. As mentioned, the intensity of mixing affects the refolding yield. To avoid aggregation in the tank, mixing times must be shorter than the reaction rate of aggregation. However, in industrial scales large tank reactors exhibit low mixing efficiencies. Efforts to improve mixing in large scale are therefore inevitable [31]. A scaleable, efficient mixing device is an oscillatory flow reactor, invented by Middelberg et al. [36]. The mixing chamber is a column, that contains the refolding buffer. It is divided in eight sections by seven flat ring baffles. The fluid is oscillated through a piston at the bottom of the column. Mixing is controllable through the frequency and the amplitude of the piston. Unfolded protein can be fed continuously into the column, either at one or two feed points. Compared to a standard fed-batch mode in a stirred tank, refolding yields could be almost doubled by this approach [37]. Another possibility to control the intensity of mixing is to involve a static mixing device which was protected by patents of St. John et al. [38] and Schlegl [39]. Here, the refolding buffer is pumped through a static mixer. The concentrated denatured protein is added to the conduit via the inlet upstream of the mixing device. This system achieves at least as good yields as conventional methods. It has the advantages of scalability, higher throughput and robustness of the process. Schlegl extended the approach of a static mixer through the recirculation of the renaturation buffer (Figure 4). Mixing times can be adjusted by the feed time of the denatured and reduced protein solution and by the recirculation flow. A fast collapse of the protein is assumed immediately after folding is initiated. The resulting conformation contains native-like secondary structures and is called the "molten globule" intermediate. These intermediates are often stable under non-denaturing conditions [40]. Through the use of a plug flow reactor prior to the refolding tank, the residence time can be adjusted, necessary for the formation of a stable intermediate. This stabilized conformation is less prone to aggregation while the buffer recirculates and further denatured protein is added. Another refolding method is reversed dilution. Most dilution methods feed the denatured protein solution to the refolding buffer. In reversed dilution the concentration of the denaturant as well as of the protein is decreased simultaneously, as the refolding buffer is fed to the solubilized inclusion bodies. He et al. used this approach to refold a staphylokinase variant [41]. 
Current patent literature suggests that fed-batch and simple dilution is not covered by patents, but for several mixing devices patents have been filed.

\section{Solubilization of inclusion bodies}

Solubilization and refolding are often interrelated. The solublization agent influences the refolding conditions. Earlier studies on the structure of inclusion bodies disclosed native or native-like structures coexisting with $\beta$-forms [42,43]. If the inclusion bodies can be solubilized under conditions where these structures can be conserved, refolding may results in clearly higher yields. Conventional solubilization agents are high concentrations of chaotropes like urea or guanidine hydrochloride that denature the target protein completely. Thus gentle solubilization methods are necessary to keep the secondary native structures that occur in the inclusion bodies. For example, McCoy patented a solubilization process for somatotropin inclusion bodies. These inclusion bodies are soluble in low concentrations of urea (around 2 M) at a pH of 12 [44]. Another uncommon solubilization approach was filed by Yong-Jun et al. [45]. They used organic solvents such as n-propyl alcohol or isopropyl alcohol including $0.05 \% \beta$-mercaptoethanol at a $\mathrm{pH}$ around 12 and temperatures of $30{ }^{\circ} \mathrm{C}$ and higher. Surfactants as N-lauroyl-sarcosine or sodium dodecyl sulfate (SDS) are also used as solubilizers that do not disrupt existing structures. However, the use of surfactants is usually avoided as it requires extensive purification steps for the removal from the protein solution $[17,46]$. A total recovery of the target protein from the inclusion bodies is a fundamental goal in the overall process. Using gentle solubilization methods may result in low recovery yields. Additionally misfolded conformations and multimers in the inclusion bodies can not be dissolved and precipitate immediately after refolding is initiated [47]. Aggregation of proteins can be suppressed if definite $\mathrm{pH}$ ranges are chosen for solubilization and refolding. At a $\mathrm{pH}$ far away from the isoelectric point (pI) a protein is highly charged. Charge repulsion occurs and prevents aggregation [48]. Denaturing and refolding at alkaline $\mathrm{pH}$ and subsequent slow reduction of the $\mathrm{pH}$ near the $\mathrm{pI}$ can support renaturation and was invented by Xinli [49]. Pizarro et al. filed a patent for a process that also focuses on the $\mathrm{pH}$ in the solubilization and renaturation process [50]. Inclusion bodies were solubilized at $\mathrm{pHs}$ greater than 9 and refolding was also accomplished at strong alkaline conditions (pHs between 9 and 11).

It seems that protein solubilization with chaotropic agents is not covered by patents and we have a freedom to operate. When it comes to solubilization a high $\mathrm{pH}$ the filed application of Pizarro et al. must be taken into consideration 


\section{Refolding buffer composition: Additives and folding aids}

Direct dilution of the denatured and reduced protein in the refolding buffer is a simple and fast method. However, renaturation steps require a carefully optimized buffer composition to attain reasonable yields. Appropriate additives play here a decisive role. They have to meet following requirements: (1) Improve clearly the refolding yield, (2) preserve the costeffectiveness of the overall process, (3) do not disturb subsequent purification steps and (4) are removable from the final product during the purification process.

Hydrophobic interactions and hydrogen bonds are responsible for the aggregation of proteins. Primarily, unfolded proteins and folding intermediates are prone to aggregation. The addition of low molecular additives or detergents to the refolding buffer reduces aggregation and in consequence precipitation during the renaturation process. Usually, these compounds can be easily removed after the refolding step. Likely, they support the solubility and stability of the native, denatured and intermediate states [51]. The most frequently used additive is L-arginine and it seems that the addition of this compound for enhancing solubility is not protected by a patent. Usually, it is added to the refolding buffer in concentrations of 0.4 to $0.8 \mathrm{M}[52,53]$. Liu et al. [54] reported, that L-arginine temporarily stabilizes the denatured proteins as well as early partially folded intermediates and refolded protein. Through specific interactions Larginine slows down conformational movement and consequently protein-protein association during the refolding process [55]. L-arginine as folding additive, especially in industrial scale, is very costly. Chaotropic agents as guanidine hydrochloride and urea can also be used as refolding additives. This, however, requires denaturant concentrations that do not destabilize the native state of the protein [51]. One explanation of the mode of action of urea and guanidine hydrochloride as protein stabilizing agents is the preferential interaction theory. It is considered, that protein stabilizing factors are based on direct protein-denaturant interactions [56]. Pike and Acharya investigated the interactions between urea and lysozyme [57]. Subtle conformational changes took place within the crystal structure of lysozyme upon exposure to urea. These changes were observed at regions of the surface of the molecule, that are known to be relatively flexible. Previous studies indicated that urea and guanidine hydrochloride, present in non-denaturing concentrations, interact with the protein through multiple hydrogen bonds $[56,57,58]$.

Shiraki et al. [59] invented a new refolding additive which is a derivative of arginine. They proofed, that L-argininamide is a better refolding additive compared to the widely used Larginine [60]. For lysozyme the refolding yield was 1.7-fold higher in the presence of argininamide than for arginine. In the case of bovine carbonic anhydrase the improvement of the final refolding yield was 1.4-fold. 
A new additive was invented by Flowers and Summers [61]. Hen egg white lysozyme could be successfully refolded at high protein concentrations using ethylammonium nitrate (EAN). Examinations of the effect of EAN on the thermal properties of the enzyme showed, that EAN acts as denaturant. Proteins can be denatured with EAN and refolded by simple dilution, resulting in reasonable refolding yields at high protein concentrations. It is supposed, that the ethyl residue of EAN interacts with the hydrophobic patches and suppresses aggregation. The charged ammonium group is assumed to stabilize the secondary structure through electrostatic interactions. EAN has the main advantage of being easily removed by desalting methods [62]. A similar approach was patented by Peters et al. [63]. They presented that chemical denatured protein can be successfully refolded in presence of secondary and tertiary amines. Adding triethanolamine- $\mathrm{H}_{2} \mathrm{SO}_{4}$ in concentrations around $1 \mathrm{M}$ showed a good refolding efficiency for recombinant interleukin-4. For bovine pancreatic trypsin Tris(hydroxymethyl)-aminoethane (TRIS) in combination with $\mathrm{H}_{2} \mathrm{SO}_{4}$ appeared as suitable agent for renaturation.

Fluorine compounds are also potential renaturants, as invented by Lohr et al. [64]. They could renature human serum albumin after heat denaturation by adding trifluoroethanol to the solution. Examinations with different fluorine derivatives indicated, that compounds with a trifluoromethyl group and a vicinal hydroxyl group are most effective for refolding.

Other additives, used in protein folding technology are cyclodextrins. These cyclic glucose oligosaccharides are able to prevent aggregation through non-covalent inclusion complexes with the hydrophobic patches of aggregation prone intermediates. Patents are filed, using this technology $[65,66]$. Refolding of bovine carbonic anhydrase and recombinant endostatin showed much higher yields, if $\alpha$-cyclodextrin was added to the renaturation buffer [67]. Cyclodextrins are also applied in the approach "artificial chaperoning". This concept was introduced by Rozema et al. [68] in 1995 and is similar to the function of the natural molecular chaperones. It comprises two steps: In the first step detergent molecules are added to capture the non-native species of the protein by forming a protein-detergent complex. Aggregation and also native refolding is disabled. To start renaturation B-cyclodextrin is added in the second step. It strippes off the detergent from the protein-detergent complexes and allows the protein to form its native conformation. There are three major cyclodextrins with six, seven and eight glucose units $(\alpha-, \beta-, \gamma$-cyclodextrin, respectively). Cycloamylose has more glucose units, usually between 17 and hundred. Machida et al. [69,70] invented the use of cycloamylose as additive in refolding experiments. In combination with dedicated detergents superior refolding yields could be achieved in comparison to the corresponding conventional $\alpha$-, $\beta$ - and $\gamma$-cyclodextrins.

Another stripping agent was reported by Khodagholi et al. [71]. They used alginate instead of cyclodextrins. Alginate is a linear polysaccharide that consists of $\beta$-D-mannuronic acid and $\alpha$ - 
L-guluronic acid. Electrostatic forces provoke the interaction of the alginate with oppositely charged detergents [72]. Refolding of alkaline phosphatase in dodecyl trimethlyammonium bromide (DTAB) and subsequent stripping of the charged detergent with alginate resulted in high recovery yields of native protein [71].

Reversed micelles are also an option for the renaturation of protein derived from inclusion bodies. They are formed, when mixtures of surfactants, water and nonpolar solvents are combined in defined concentrations. The surfactant aerosol OT (AOT, sodium dioctyl sulfosuccinate) is very common for this system. Aqueous nanoscaled droplets are formed, stabilized by surfactants. Through micelles, protein molecules are separated of each other. Intermolecular interactions are reduced and aggregation is prevented. The polar groups are concentrated inside, whereas the lipophilic groups extend to the non-polar organic solvent. The size of the aqueous droplet inside of the micelle depends on the conditions of the system. Variables as surfactant to water ratio, ionic strength, surfactant and protein concentration have to be varied until the size of a micelle conforms to the size of a protein molecule. The total process comprises four steps: (1) The denatured protein has to be transferred into the micelles, (2) the denaturant has to be removed, (3) folding agents as redox reagents can be added and (4) extraction of the renatured protein from the micelles. RNase A was successfully refolded with this system [73,74]. Compared to the conventional dilution method Sakono et al. [73] could improve refolding yields from 40 to $100 \%$. But the refolding kinetics was slower with the reversed micelle mediated system. To overcome this problem, Sakono et al. added the molecular chaperone GroEL into the reversed micelles. The kinetic was significantly improved. After one hour more than $80 \%$ activity was achieved, whereas without GroEL only $20 \%$ could be recovered.

Recently, new refolding additives were published by Pitner et al. [75]. They used ionic liquids with a specific distribution of the electron density for protein refolding. Ionic liquids or liquid salts consist usually of an organic cation and an inorganic anion. The cation has at least one electron donor region and one positive charged electrostatic region. Pitner et al. refolded several proteins in presence of ionic liquids. They showed the potency of ionic liquids in comparison to conventional additives, as for example L-arginine.

Mostly the exact mechanism of action of refolding additives is a supposition or even unclear. This makes it inevitable to determine suitable additives as well as refolding conditions for a certain protein by trial and error. It is also not clear, how far the protection of additives reaches. The current practice of patent offices is to strictly limit the invention to the presented example. Thus it is difficult to demonstrate, that a certain additive is suited for all proteins. In particular certain compounds are protected by patents although a general patent on the addition of additives does not exist. An overview of additives is provided in Table 1 . We 
assume that there are many more compounds have been claimed as additives but often only connection with a certain protein.

\section{High-pressure disaggregation and folding}

Unfolding of many proteins under high hydrostatic pressure has been known for more than 90 years [76]. Pressure is a useful tool to study thermodynamics of proteins, as well as unfolding and refolding processes $[77,78]$. In general, dissociation of multimeric proteins is facilitated at pressures between 1000 and 3000 bar. For total unfolding pressures up to 8000 bar are usually necessary. The specific volume of a protein state, formed at high pressures, dominate the renaturation process. Simple thermodynamics is responsible for this observation. The pressure dependent change of Gibbs free energy between two states corresponds to their difference in specific volume. Several factors are assumed to cause these volume decreases. Inside folded proteins or at interfaces of oligomeric proteins there are cavities and internal voids, that favor unfolding or dissociation. These intra- and intermolecular cavities are dissected during unfolding processes. Electrostatic interactions are disrupted and the electrostriction of water molecules around free charged groups is caused. Moreover, hydrophobic patches and polar groups are exposed to hydration [79]. High pressure destabilizes native proteins. In magnitude, the occurring change of the specific volume during unfolding is quite small. It is only 0.5 to $1 \%$ of the total specific volume, but nevertheless significant [80].

Pressure induced unfolding is favored as it is reversible and usually only low concentrations or even no chaotropic agents have to be added. Conventional solubilization techniques of inclusion bodies comprise highly concentrated guanidine hydrochloride or urea buffers. Usually proteins are completely unfolded in these chaotropic agents. The combination of high hydrostatic pressure and low concentrations of guanidine hydrochloride prevents aggregation during refolding [81]. Applying high pressure to aggregates or inclusion bodies results in solubilization under gentle conditions. Folding can be started from structures, that are less interrupted or even possess some secondary structure. Studies with RNase A showed, that pressure denatured RNase A keeps a significant degree of secondary structure. Generally it can be stated, that the pressure denatured states of proteins contain more secondary structure than the temperature or chemical denatured states [77].

$\beta$-lactamase was successfully refolded from inclusion bodies applying 2000 bar for $48 \mathrm{~h}$, as shown an example of a patent, filed by Randolph et al. [82,83]. Catalytic activity was observed even without a chaotropic agent in the renaturation buffer. At higher concentrations of guanidine the total protein concentration increased and the soluble amount of $\beta$-lactamase as well as the recovered activity remained nearly constant. Applying high pressures in the absence of guanidine hydrochloride can be also used as purification step. The total solubilized 
protein increased with the concentration of guanidine, whereas the solubilized concentration of the target protein $\beta$-lactamase remained the same. As renaturation tool high-pressure has the advantage, that it dissociates aggregates while it favors the native conformation. During refolding it prevents and reverses aggregation, which has already taken place. This technology was invented by Robinson et al. [84]. Additives as urea of guanidine hydrochloride can support this process. That is a major benefit compared to conventional refolding methods, as dilution or dialysis. Aggregation is reversible and higher yields of native protein can be achieved. Even high protein concentrations lead to reasonable refolding yields. As for conventional refolding methods, like dilution, refolding conditions have to be optimized for high pressure renaturation as well. Additives and redox systems have to be tested to improve refolding yields. Using glycerol as folding additive for the enzyme rhodanese in combination with the high-pressure technology nearly doubled the renaturation yield [85]. Other parameters as temperature or agitation during pressure treatment can also promote refolding yields, as patented by Randolph et al. [86]. They showed, that recombinant human growth hormone (rhGH) totally refolded at $60{ }^{\circ} \mathrm{C}$ and 2000 bar. Stirring the solution at these conditions was found to increase the refolding yield as well as the folding kinetics. Refolding at high pressures in the presence of specific binding agents was filed by Seefeldt et al. [87]. As binding agents small organic molecules, polypeptides and nucleic acids are a possibility for improvements of renaturation yields.

In the case of biopharmaceutical preparations, aggregates can induce immune responses, including anaphylactic reactions in patients. The consequences can be fatal. Aggregates do not only occur during refolding. In processing steps as filtration, ultrafiltration, chromatography, vial filling, crystallization and so on, protein aggregation can be observed [88].

The use of high-pressure could be a valuable tool in the preparation and storage of pharmaceutical drugs to prevent aggregation. In addition, high-pressure technology to disaggregate and refold proteins is efficient and cost-effective. Refolding at high protein concentrations does not require large-scale dilution and additional concentration steps. The plant throughput can be increased which is favorable in industrial production processes. Currently several patents have been filed to protect high pressure refolding of recombinant proteins and dissolution of aggregates. In this respect we assume a very limited freedom of operation and a contact with the owners is advisable.

\section{On-column refolding}

There are three different approaches for on-column refolding: (1) Dilution of denaturants by size exclusion chromatography, (2) retention of the denatured protein on a chromatographic 
phase and subsequent removal of the denaturant and (3) immobilization of a folding catalyst on a chromatographic phase, where the column acts as a catalyzed refolding reactor [89]. Oncolumn refolding offers the advantage of refolding and simultaneous purification.

Refolding using size exclusion chromatography is based on a gradual removal of the denaturant. Aggregates, intermediates and native protein are separated by their different diffusion properties in the stationary phase. The denatured protein has a high hydrodynamic radius and is excluded from the gel pores. During refolding the protein size decreases and gel pores are easier accessible. $\mathrm{Gu}$ et al. presented, that the overall refolding yields of a singlechain antibody fragment ( $\mathrm{scFv}$ ) with SEC are comparable to yields achieved with batch dilution [90]. Using an urea gradient resulted in slightly higher yields. The highest yield was obtained with a combined urea and $\mathrm{pH}$ gradient. However, refolding by SEC has the key advantage over conventional dilution, that the material on the column is fractionated by size. A new method applying SEC for refolding is a continuous process. Intermediates and aggregates are separated from the native refolded protein and can be reconstituted to the feed solution. An extensive study was done with $\alpha$-lactalbumin as model protein using pressurized continuous annular chromatography (Figure 5). Through recycling of intermediates and aggregates the refolding yield could be improved considerably, which was shown and patented by Necina et al. [91,92].

Adsorption of a denatured protein on a solid matrix is supposed to prevent aggregation through separation of the individual protein molecules from each other during refolding. This approach was firstly invented by Creighton [93]. After adsorption of the unfolded protein on an ion exchange matrix he initiated refolding. As for SEC, P-CAC with an ion-exchange resin achieved better refolding yields for $\alpha$-lactalbumin, especially when aggregates were reconstituted to the refolding step [79,94]. Another method is dual gradient ion-exchange chromatography (IEC). The denatured protein is eluted by gradual decrease of the denaturant concentration and increase of the $\mathrm{pH}$. The protein refolds gradually and compared to batch dilution higher refolding yields can be attained [95]. Refolding conditions using ion-exchange have to be carefully optimized. Otherwise non-specific protein-matrix interactions can occur and no refolding takes place. However, if optimal conditions are found, denatured protein can be refolded at significantly higher concentrations as in batch dilution [84]. The principle of protein adsorption on an ion exchange matrix can be used in expanded bed adsorption (EBA) chromatography. In EBA chromatography the void fraction is increased which allows the application of particle containing feedstocks. Especially in large scale applications EBA chromatography is a useful tool, has large volumes can be processed. Compared to conventional on-column refolding with an ion exchange resin, similar refolding yields can be attained with EBA chromatography [96]. 
Simulated moving bed has been used for continuous refolding of proteins [97, 98] but it seems that the method has been never claimed for on-column refolding. Still one might consider that certain configurations or column designs for SMB may be protected by patents.

Introducing a $\mathrm{N}$ - or $\mathrm{C}$-terminal polyhistidine-tag allows refolding on a solid matrix based on immobilized metal affinity chromatography (IMAC). Immobilized divalent metal ions (for example $\mathrm{Ni}^{2+}$ or $\mathrm{Cu}^{2+}$ ) form high-affinity complexes with the polyhistidine-tag in presence of high concentrations of denaturants as guanidine or urea. IMAC offers the advantage, that solubilized inclusion bodies are firstly purified and then refolded. Applying IMAC offered superior results for the purification of an anti-TNF $\alpha-\mathrm{scFv}$. A refolding yield of $77 \%$ and purity of $95 \%$ could be obtained [99]. The potency of this method was proofed for several proteins, containing a polyhistidine-tag [100,101,102].

Hydrophobic interaction chromatography (HIC) is also an option for on-column refolding. Aggregation can be suppressed through hydrophobic interactions between ligands of the matrix and protein molecules. For lysozyme refolding yields increased with rising hydrophobic strength of the resin. Adding glycerol to the eluent improved the specific activity of the renatured lysozyme [103].

Another set-up for on-column refolding is, to immobilize folding catalysts and artificial chaperones. In vivo conditions are mimicked and supposed to improve refolding yields. Tsumoto et al. [104] used the foldase oxidoreductase, immobilized on Nhydroxysuccinimide-activated Sepharose $4 \mathrm{FF}$, to refold a single-chain antibody fragment and prevented the aggregation of the target protein in the refolding step. An engineered chaperone has been also used for improvement of refolding [108,109]. This strategy is not well accepted in industry since it is expensive and a lot of chaperone must be produced because they act in a stoichiometric manner. Patents have been withdrawn and in this respect we also have freedom to operate, presumably somebody finds an inexpensive alternative to produce minichaperones.

A novel approach using zeolite was invented by Mizukami et al. [105,106]. Zeolites are crystalline porous aluminosilica compounds. These tectosilicates are made up of $\mathrm{AlO}_{4}$ and $\mathrm{SiO}_{4}$ tetrahedra that share the corners. In industry, zeolites are widely used as cationic ion exchangers and catalysts. The main advantage of zeolite is, that proteins can be adsorbed in the presence of denaturants. The zeolite is suspended in the denatured protein solution and after washing away the chaotropic agent, the target protein can be desorbed with buffer containing detergents as polyethylene glycol (PEG) and Tween 20.

On-column refolding provides a good alternative to common methods [107] especially when the refolding yield in batch refolding is very low. The Creighton patent [92] covering a wide range on column refolding methods has a priority date of April $1^{\text {st }} 1986$ and is 
meanwhile expired. So we assume freedom of operation for a conventional on column refolding passing a denatured protein solution over a chromatography column and elution by a kosmotropic buffer. Tough several more sophisticated including continuous chromatographic methods have been filed (Table 1) a general continuous chromatography refolding procedure has not been patented. In particular continuous annular chromatography [92] for continuous refolding has been claimed.

\section{Conclusion}

E. coli is a widely used expression system for the heterologous proteins. The detailed knowledge of the genetics, simple cultivation conditions and short generation times are attractive in commercial and research applications. However, overexpression leads mostly to the accumulation of insoluble inclusion bodies in the cytoplasm of E. coli and recovery of native protein requires an elaborative renaturation step. Thus, it is desirable to establish refolding methods, that are applicable for a wide range of different proteins. New approaches and methods have to be investigated to explore their potential as "generic" refolding tools. For manufacturing scale novel concepts have to be evaluated regarding their scalability and economic features. In general, batch and fed batch refolding methods are not covered by patents. The use of improved solubilization and refolding additives is broadly covered, and it is advisable, to check patent literature to avoid infringement. A similar situation has been found for continuous refolding. The freedom to operate is given for technical refolding. There is enough room, to exploit the power of inclusion body technology for further innovative protein products. 


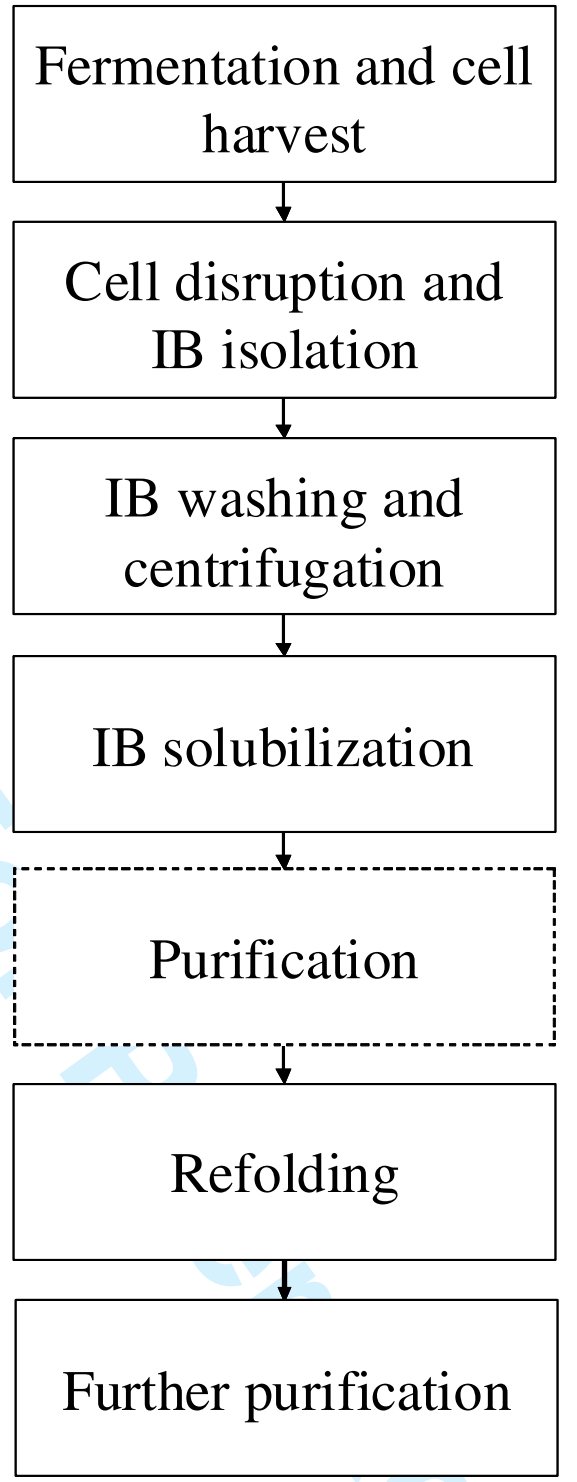

Figure 1: Flow diagram for the protein recovery expressed as inclusion bodies in E. coli. - IB: Inclusion bodies. 
1

2

3

4

5

6

7

8

9

10

11

12

13

14

15

16

17

18

19

20

21

22

23

24

25

26

27

28

29

30

31

32

33

34

35

36

37

38

39

40

41

42

43

44

45

46

47

48

49

50

51

52

53

54

55

56

57

58

59

60

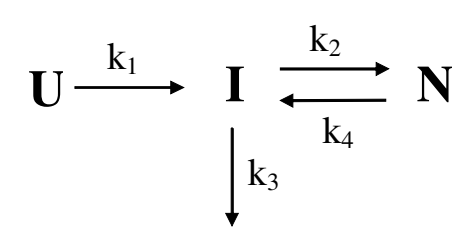

A

Figure 2: Simplified refolding pathway of a denatured-reduced protein. - U: unfolded and reduced protein, I: intermediate state, $\mathrm{N}$ : native state, $\mathrm{A}$ : aggregated state, $\mathrm{k}$ : reaction rate constant. 


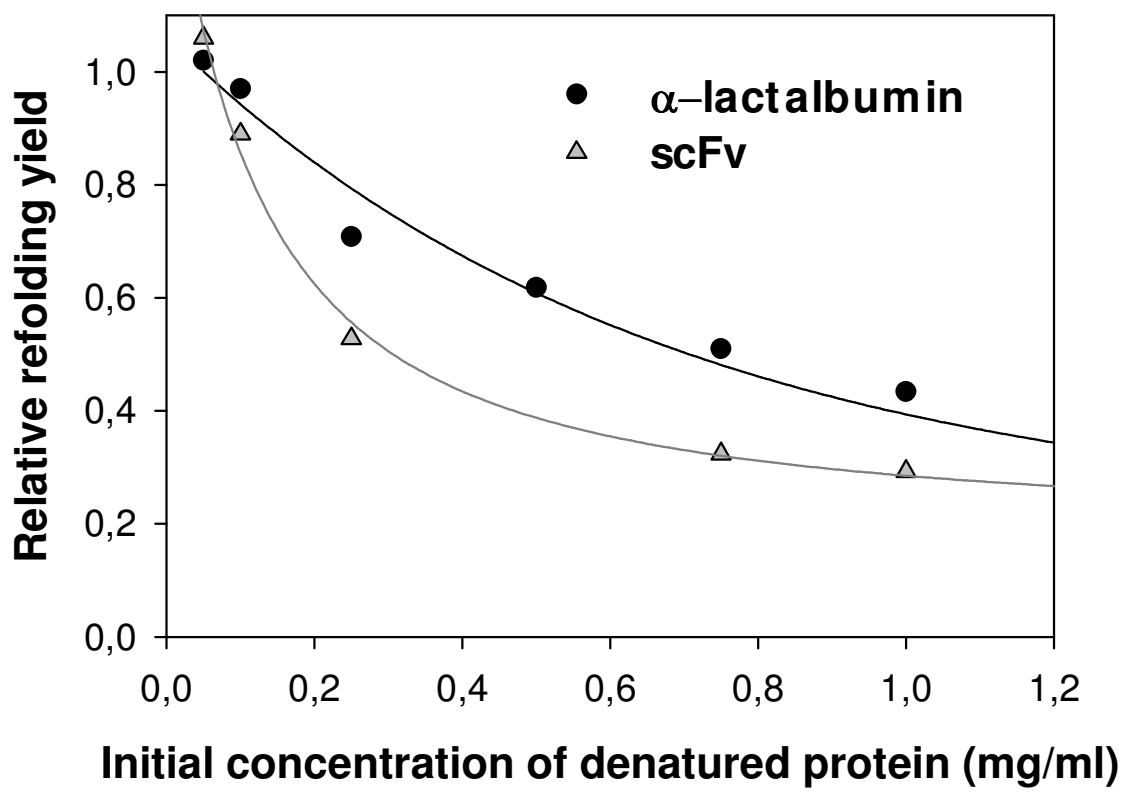

Figure 3: Relative refolding yield dependent on the initial concentration of denatured protein for $\alpha$-lactalbumin and a single-chain antibody fragment ( $\mathrm{scFv})$. 


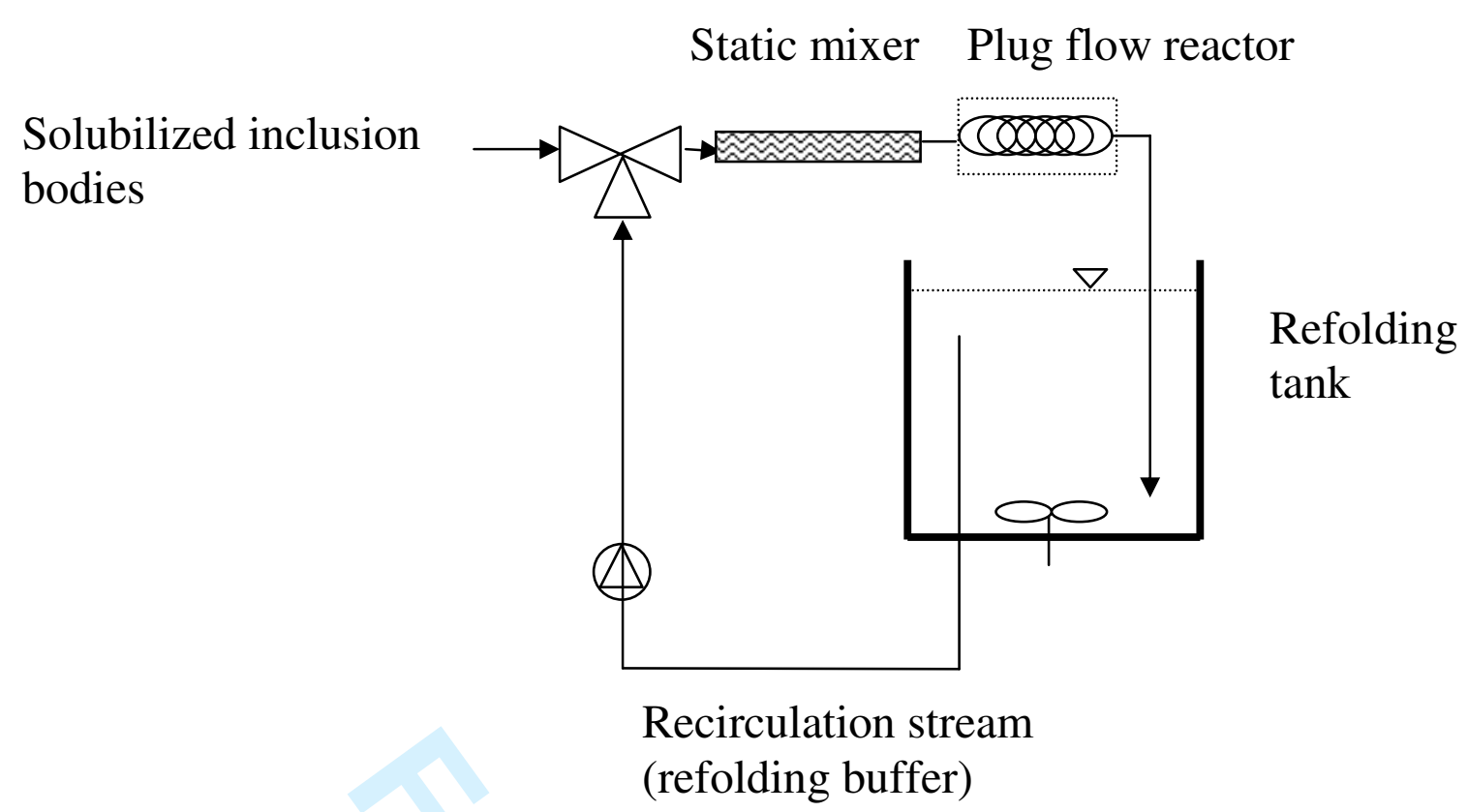

Figure 4: Schematic illustration of a refolding device including a static mixer and plug flow reactor [39]. 


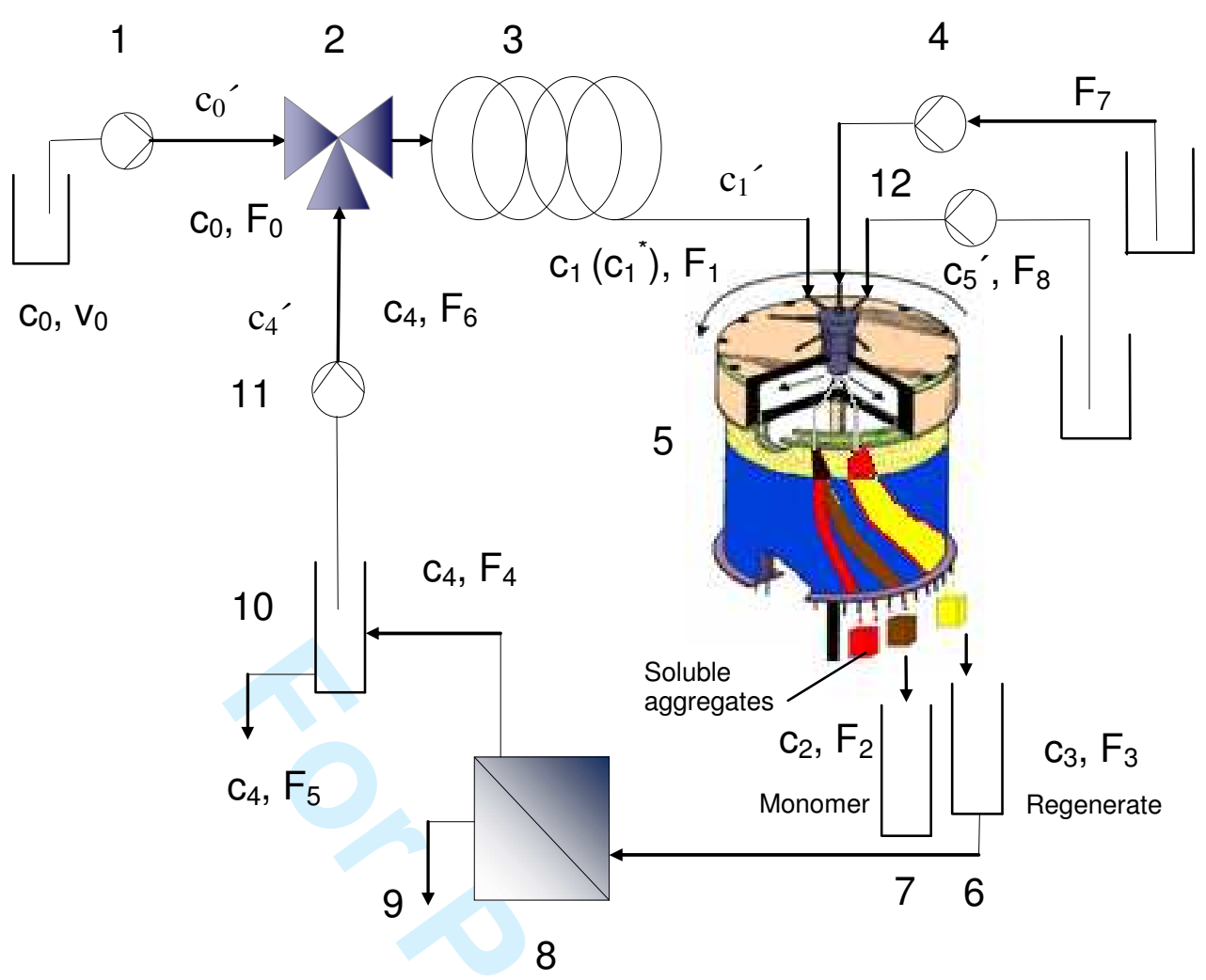

Figure 5: Experimental setup of continuous refolding by annular chromatography with recycling of aggregates. 1 feed pump delivering denatured protein; 2 mixer for blending of fresh feed with recycled feed after concentration by tangential flow filtration; 3 reaction loop; 4 eluent pump for the annular chromatography system; 5 annular chromatography system (a) 6 collecting device for regenerate fractions; 7 collecting device for monomeric protein fraction; 8 tangential flow filtration device; 9 permeate outlet; 10 vessel for collection of concentrated aggregates and 11 recycling pump; 12 pump for delivering regeneration buffer. 
Table 1: Overview of additives for refolding of proteins, patents are bold

Additive

L-Arginine Urea

Guanidine hydrochloride

L-Argininamide

Ethylammonium nitrate

(EAN)

Secondary and tertiary amines

Fluorine derivatives

Cyclodextrin $(\alpha-, \beta-, \gamma-)$ Ionic liquid

Cycloamylose ${ }^{*}$ )

Alginate*)

Reversed Micelles (AOT)*)

*) stripping agent when a surfactant is used for stabilisation of protein
Reference

$0.4-0.8 \mathrm{M}$

$\leq 2.0 \mathrm{M}$

$\leq 1.0 \mathrm{M}$

$\leq 2.0 \mathrm{M}$

51

$0.5-50.0 \%$

$\mathbf{5 9}, 60$

$\mathbf{6 1 , 6 2}$

$$
\begin{gathered}
\leq 1.5 \mathrm{M} \\
0.5-95 \% \\
5.0-10.0 \% \\
0.25-5.0 \mathrm{M} \\
16 \mathrm{mM}
\end{gathered}
$$$$
63
$$$$
0.25-3.0 \%
$$

\section{4}

66, 67

75

6970

71,72

73 
Table 2: Overview of patents and literature for various refolding techniques.

\begin{tabular}{lcc}
\hline Homogenous and heterologous techniques & Patents & Literature reference \\
\hline Solubilization of inclusion bodies & $44,45,49,50$ & 47,48 \\
Batch dilution & & 32,33 \\
Continuous dilution & $28,29,34$ & $30,31,32,33,41$ \\
Additives & $59,61,63,64,65,66,70$ & $51,52,53,60,62,67,68,69,71,72,73,74$ \\
Oscillator and other mixing devices & $36,38,39$ & 37 \\
On column refolding & $92,93,105$ & $91,94,96,99,103$ \\
Immobilized folding catalysts & $108 *$ & $104,109,110$ \\
High pressure refolding & $82,84,86,87$ & $52,81,85$ \\
\hline
\end{tabular}

*Application has been withdrawn 


\section{References}

[1] Terpe, K., Overview of bacterial expression systems for heterologous protein production: From molecular and biochemical fundamentals to commercial systems. Appl. Microbiol. Biotechnol. 2006, 72, 211-222.

[2] Baneyx, F., Recombinant protein expression in Escherichia coli. Curr. Opin. Biotechnol. 1999, 10, 411 421.

[3] Schmidt, F. R., Recombinant expression systems in the pharmaceutical industry. Appl. Microbiol. Biotechnol. 2004, 65, 363-372.

[4] Georgiou, G., Segatori, L., Preparative expression of secreted proteins in bacteria: status reports and future prospects. Curr. Opin. Biotech. 2005, 16, 538-545.

[5] Chen,C., Snedecor, B., Nishihara, J. C., Joly, J. C., McFarland, N., Andersen, D. C., Battersby, J. E., Champion, K. M., High-level accumulation of a recombinant antibody fragment in the periplasm of Escherichia coli requires a triple-mutant (degP prc spr) host strain. Biotechnol. Bioeng. 2004, 85, 463474.

[6] Baneyx, F., Mujacic, M., Recombinant protein folding and misfolding in Escherichia coli. Nat. Biotechnol. 2004, 22, 1399-1408.

[7] Swartz, J. R., Advances in Escherichia coli production of therapeutic proteins. Curr. Opin. Biotech. 2001, 12, 195-201.

[8] Przybycien, T. M., Dunn, J. P., Valax, P., Georgiou, G., Secondary structure characterization of $\beta$ lactamase inclusion bodies. Protein Eng. 1994, 7, 131-136.

[9] Vallejo, L. F., Rinas, U., Strategies for the recovery of active proteins through refolding of bacterial inclusion body proteins. Microb. Cell Fact. 2004, 3,11-23.

[10] De Bernardez Clark, E., Protein refolding for industrial processes. Curr. Opin. Biotech. 2001, 12, 202207.

[11] Graumann, K., Premstaller, A., Manufacturing of recombinant therapeutic proteins in microbial systems. Biotech. J. 2006, 1, 164-186.

[12] Swietnicki, W., Folding aggregated proteins into functionally active forms. Curr. Opin. Biotechnol. 2006, 17, 367-372.

[13] Chen, L.-H., Huang, Q., Wan, L., Zeng, L.-Y., Li, S.-F., Li, Y.-P., Lu, X.-F., Cheng, J.-Q., Expression, purification, and in vitro refolding of a humanized single-chain Fv antibody against human CTLA4 (CD152). Protein Expr. Purif. 2006, 46, 495-502.

[14] Wan, L., Zeng, L., Chen, L., Huang, Q., Li, S., Lu, Y., Li, Y., Cheng, J., Lu, X., Expression, purification, and refolding of a novel immunotoxin containing humanized single-chain fragment variable antibody against CTLA4 and the N-terminal fragment of human perforin. Protein Expr. Purif. 2006, 48, 307-313.

[15] Cabrita, L. D., Bottomley, S. P., Protein expression and refolding - A practical guide to getting the most out of inclusion bodies. Biotechnol. Annu. Rev. 2004, 10, 31-50.

[16] Fahnert, B., Lilie, H., Neubauer, P., Inclusion bodies: Formation and utilisation. Adv. Biochem. Eng. Biotechnol. 2004, 89, 93-142. 
[17] Patra, A. K., Mukhopadhyay, R., Mukhija, R., Krishnan, A., Optimization of inclusion body solubilization and renaturation of recombinant human growth hormone from Escherichia coli. Protein Expr. Purif. 2000, 18, 182-192.

[18] Singh, S. M., Panda, A. K., Solubilization and refolding of bacterial inclusion body protein. J. Biosci. Bioeng. 2005, 99, 303-310.

[19] Kurucz, I., Titus, J. A., Jost, C. R., Segal, D. M., Correct disulfide pairing and efficient refolding of detergent-solubilized single-chain Fv proteins from bacterial inclusion bodies. Mol. Immunol. 1995, 32, 1443-1452.

[20] Misawa, S., Kumagai, I., Refolding of therapeutic proteins produced in Escherichia coli as inclusion bodies. Biopolymers (Peptide Science) 1999, 51, 297-307.

[21] Lilie, H., Schwarz, E., Rudolph, R., Advances in refolding proteins produced in E. coli. Curr. Opin. Biotechnol. 1998, 9, 497-501.

[22] Buswell, A. M., Middelberg, A. P. I., A new kinetic scheme for lysozyme refolding and aggregation. Biotechnol. Bioeng. 2003, 83, 567-577.

[23] Goldberg, M. E., Rudolph, R., Jaenicke, R., A kinetic study of the competition between renaturation and aggregation during the refolding of denatured-reduced egg white lysozyme. Biochemisty 1997, 30, 2790-2797.

[24] Kiefhaber, T., Rudolph, R., Kohler, H-H., Buchner, J., Protein aggregation in vitro an in vivo: A quantitative model of the kinetic competition between folding and aggregation. Bio/Technology 1991, 9, 825-829.

[25] De Bernardez Clark, E., Hevehan, D., Szela, S., Maachupalli-Reddy, J., Oxidative renaturation of hen egg-white lysozyme. Folding vs. aggregation. Biotechnol. Prog. 1998, 14, 47-54.

[26] Wang, W., Protein aggregation and its inhibition in biopharmaceutics. Int. J. Pharm. 2005, 289, 1-30.

[27] Hevehan, D. L., De Bernardez Clark, E., Oxidative renaturation of lysozyme at high concentrations. Biotechnol. Bioeng. 1997, 54, 221-230.

[28] Rudolph, R., Fischer, S., Process for obtaining renatured proteins. US Patent 4,933,434 (1990).

[29] Galliher, P., Continuous method of refolding proteins. US Patent 4,999,422 (1991).

[30] Buswell, A. M., Ebtinger, M., Vertés, A. A., Middelberg, A. P. I., Effect of operating variables on the yield of recombinant trypsinogen for a puls-fed dilution-refolding reactor. Biotechnol. Bioeng. 2002, 77, 435-444.

[31] Mannall, G. J., Titchener-Hooker, N. J., Chase, H. C., Dalby, P. A., A critical assessment of the impact of mixing on dilution refolding. Biotechnol. Bioeng. 2006, 93, 955-963.

[32] Katoh, S., Terashima, M., Kishida, H., Yagi, H., Refolding efficiency of lysozyme in fed-batch system. J. Chem. Eng. 1997, 30, 964-966.

[33] Katoh, Y., Farshbaf, M., Kurooka, N., Nohara, D., Katoh, S., High yield refolding of lysozyme and carbonic anhydrase at high protein concentrations. J. Chem. Eng. Japan 2000, 33, 773-777.

[34] Buus, S., Ferré, H., Ruffet, E., A method for refolding of proteins. WO 02057296 (A1) and US20040116663 (A1) (2002).

[35] Ferré, H., Ruffet, E., Nielsen, L.-L. B., Nissen, M. H., Hobley, T. J., Thomas, O. R. T., Buus, S., A novel system for continuous protein refolding and on-line capture by expanded bed adsorption. Protein Sci. 2005, 14, 2141-2153. 
[36] Middelberg ,A., Lee, C. T., Mackley, M., Buswell, M., A protein refolding reactor. WO 03/002590 A2 (2001).

[37] Lee, C. T., Mackley, M. R., Stonestreet, P., Middelberg, A. P. I., Protein refolding in an oscillatory flow reactor. Biotechnol. Lett. 2001, 23, 1899-1901.

[38] St. John, R., Luk, J., Le, T., Method and system for in vitro protein refolding. WO 2007/016272 A1 (2007).

[39] Schlegl, R., Method for refolding a protein. EP1845103 A1 (2007) and US7651848 B2 (2010).

[40] Bam, N. B., Cleland, J. L., Randolph, T. W., Molten globule intermediate of recombinant human growth hormone: Stabilization with surfactants. Biotechnol. Prog. 1996, 12, 801-809.

[41] He, J., Wang, G., Xu, R., Feng, J., Wang, J., Su, H., Song, H., Refolding of a staphylokinase variant Y1Sak by reverse dilution. Appl. Biochem. Biotechnol. 2008, 151, 29-41.

[42] Oberg, K., Chrunyk, B. A., Wetzel, R., Fink, A. L., Native like secondary structure in Interleukin-1B inclusion bodies by attenuated total reflectance FTIR. Biochemistry 1994, 33, 2628-2634.

[43] Ventura, S., Villaverde, A., Protein quality in bacterial inclusion bodies. Trends Biotechnol. 2006, 24, 179-185.

[44] McCoy, K. M., Method for solubilization and naturation of somatotropins utilizing low urea concentration. US5151501 A (1992).

[45] Yong-Jun, L., Hong-Kyun, L.,Kyuboem, H., Process for the preparation of active somatotropin from inlcusion bodies. US6,987,173 B2 (2006).

[46] Jevševar, S., Gaberc-Porekar, V., Fonda, I., Podobnik, B., Grdadolnik, J., Menart, V., Production of nonclassical inclusion bodies from which correctly folded protein can be extracted. Biotechnol. Prog. $2005,21,632-639$.

[47] Freydell, E. J., Ottens, M., Eppink, M., van Dedem, G., van der Wielen, L., Efficient solubilization of inclusion bodies. Biotechnol. J. 2007, 2, 678-684.

[48] Chi, E. Y., Krishnan, S., Randolph, T. W., Carpenter, J. F., Physical stability of proteins in aqueous solution: Mechanism and driving forces in nonnative protein aggregation. Pharma. Res. 2003, 20, 13251336.

[49] Xinli, L., Universal procedure for refolding recombinant proteins. US 6,583,268 B2 (2003).

[50] Pizarro, S., Sanchez, A., Schmelzer, C. H., Refolding of recombinant proteins. US2008/0125580 A1 (2008).

[51] De Bernardez Clark, E., Schwarz, E., Rudolph, R., Inhibition of aggregation side reactions during in vitro protein refolding. Methods Enzymol. 1999, 309, 217-236.

[52] Lee, S.-H., Carpenter, J. F., Chang, B. S., Randolph, T. W., Lim, Y.-S., Effects of solutes on solubilization and refolding of proteins from inclusion bodies with high hydrostatic pressure. Protein Sci. 2006, 15, 304-313.

[53] Arora, D., Khanna, N., Method for increasing the yield of properly folded recombinant human gamma interferon from inclusion bodies. J. Biotechnol. 1996, 52, 127-133.

[54] Liu, Y.-D., Li, J.-J., Wang, F.-W., Chen, J., Li, P., Su, Z.-G., A newly proposed mechanism for arginine-assisted protein refolding-not inhibiting soluble oligomers although promoting a correct structure. Protein Expr. Purif. 2007, 51, 235-242.

[55] Baynes, B. M., Wang, D. I. C., Trout, B. L., Role of arginine in the stabilization of proteins against aggregation. Biochemistry 2005, 44, 4919-4925. 
[56] Bhuyan, A. K., Protein stabilization by urea and guanidine Hydrochloride. Biochemistry 2002, 41, 13386-13394.

[57] Pike, A. C. W., Acharya, K. R., A structural basis for the interaction of urea with lysozyme. Protein Sci. 1994, 3, 706-710.

[58] Dunbar, J., Yennwar, H. P., Banerjee, S., Luo, J., Farber, G. K., The effect of denaturants on protein structure. Protein Sci. 1997, 6, 1727-1733.

[59] Shiraki, K., Hamada, H., Fukuda, Y., Fukuda, K., Protein refolding additive and method for refolding protein using the same. JP2007332093 A (2007).

[60] Hamada, H., Shiraki, K., L-argininamide improves the refolding more effectively than L-arginine. $J$. Biotechnol. 2007, 130, 153-160.

[61] Flowers, R. A. II, Summers, C. A., Uses of alkylammonium salts in protein renaturation. WO0170761 A1 (2001).

[62] Summers, C. A., Flowers, R. A. II, Protein renaturation by the liquid organic salt ethylammonium nitrate. Protein Sci. 2000, 9, 2001-2008.

[63] Peters, J., Minuth, T., Process for renaturation of recombinant, disulfide containing proteins at high protein concentrations in the presence of amines. EP 1314739 (2003) and US 2005/0014933 (2005).

[64] Lohr, F., Pawlik, A., Motschmann, H., Bree, M., Vieira, E., Welle, A., Renaturation of proteins. US 6,022,722 (2000).

[65] Sharma, A., Kauppiah, N., Use of cyclodextrins for protein renaturation. WO9638468 (1996).

[66] Xie, D., Grulich, P., Erickson, J., Method for refolding recombinant endostatin. WO0160839 (2001).

[67] Sharma, A., Kauppiah, N., Cyclodextrins as protein folding aids. Biochem. Biophys. Res. Commun. 1995, 211, 60-66.

[68] Rozema, D., Gellman, S. H., Artifical chaperones: Protein refolding via sequential use of detergent and cyclodextrin. J. Am. Chem. Soc. 1995, 117, 2373-2374.

[69] Machida, S., Ogawa, S., Xiaohua, S., Takaha, T., Fujii, K., Hayashi, K., Cycloamylose as an efficient artificial caperone for protein refolding. FEBS Lett. 2000, 486, 131-135.

[70] Machida, S., Hayashi, K., Artificial chaperon kit. US 6,852,833 B1 (2005).

[71] Khodagholi, F., Eftekharzadeh, B., Yazdanparast, R., A new artificial chaperone for protein refolding: sequential use of detergent and alginate. Protein J. 2008, 27, 123-129.

[72] Neumann, M. G., Schmitt, C. C., Iamazaki, E. T., A fluorescence study of the interactions between sodium alginate and surfactants. Carbohydr. Res. 2003, 338, 1109-1113.

[73] Sakono, M., Kawashima, Y., Ichinose, H., Maruyama, T., Kamiya, N., Goto, M., Direct refolding of inclusion bodies using reversed micelles. Biotechnol. Prog. 2004, 20, 1783-1787.

[74] Hagen, A. J., Hatton, T. A., Wang, D. I. C., Protein refolding in reversed micelles. Biotechnol. Bioeng. 2006, 95, 285-294.

[75] Pitner, W.-R., Eichhorn, J., von Hage, J., Leland, P. A., Scott, G. B. I., Method and agent for refolding of proteins. WO2009046840 A1 (2009).

[76] Bridgman, P. W., The coagulation of albumen by pressure. J. Biol. Chem. 1914, 19, 511-512.

[77] Ribó, M., Font, J., Benito, A., Torrent, J., Lange, R., Vilanova, M., Pressure as a tool to study proteinunfolding/refolding processes: The case of ribonuclease A. Biochim. Biophys. Acta 2006, 1764, 461469. 
[78] Kobashigawa, Y., Sakurai, M., Nitta, K., Effect of hydrostatic pressure on unfolding of $\alpha$-lactalbumin: Volumetric equivalence of the molten globule and unfolded state. Protein Sci. 1999, 8, 2765-2772.

[79] Kim, Y-S., Randolph, T. W., Seefeldt, M. B., Carpenter, J. F., High-pressure studies on protein aggregates and amyloid fibrils. Methods Enzymol. 2006, 413, 237-253.

[80] Royer, A. C., Revisiting volume changes in pressure-induced protein unfolding. Biochimica Biochim. Biophys. Acta 2002, 1595, 201-209.

[81] Perrett, S., Zhou, J-M., Expanding the pressure technique: Insights into protein folding from combined use of pressure and chemical denaturants. Biochimica Biochim. Biophys. Acta 2002, 1595, 210-223.

[82] Randolph, T. W., Carpenter, J. F., St. John, R. J., High pressure refolding of protein aggregates and inclusion bodies. US 7,064,192 B2 (2006).

[83] St. John, R. J., Carpenter, J. F., Randolph, T. W., High pressure fosters protein refolding from aggregates at high concentrations. Proc. Nat. Acad. Sci. USA 1999, 96, 13029-13033.

[84] Robinson, A. S., Robinson, C. R., Foguel, D., Silva, J. L., Use of hydrostatic pressure to inhibit and reverse protein aggregation and facilitate protein refolding. US 7,615,617 B2 (2006).

[85] Gorovits, B. M., Horowitz, P. M., High hydrostatic pressure can reverse aggregation of protein folding intermediates and facilitate acquisition of native structure. Biochem. 1998, 37, 6132-6135.

[86] Randolph, T. W., Carpenter, J. F., St. John, R. J., Improved protein disaggregation and refolding using high pressure. EP 1434789 B1 (2008) and US 7,538,198 B2 (2009).

[87] Seefeldt, M. B., Hesterberg, L. K., Randolph, T. W., Carpenter, J. F., High-pressure refolding of proteins in the presence of binding partners. WO2008124134 A2 (2008) and US2008/0249286 A1 (2008).

[88] Cromwell, M. E. M., Hilario, E., Jacobson, F., Protein aggreation and bioprocessing. AAPS J. 2006, 8, E572-E579.

[89] Middelberg, P. J., Preparative protein refolding. Trends Biotechnol. 2002, 20, 437-442.

[90] Gu, Z., Weidenhaupt, M., Ivanova, N., Pavlov, M., Xu, B., Su, Z. G., Janson, J. C., Chromatographic methods for the isolation of, and refolding of proteins from, Escherichia coli inclusion bodies. Protein Expr. Purif. 2002, 25, 174-179.

[91] Schlegl, R., Iberer, G., Machold, C., Necina, R., Jungbauer, A., Continuous matrix-assisted refolding of proteins. J. Chromatogr. A 2003, 1009, 119-132.

[92] Necina, R., Schlegl, R., Jungbauer, A., Machold, C., Method for reconstituting a recombinant protein to its biologically active form. WO03/031465 A1 (2003) and US 7,060,460 B2 (2006).

[93] Creighton, T. E., A process for the production of a proteins. WO8605809 (1986)

[94] Machold, C., Schlegl, R., Buchinger, W., Jungbauer, A., Continuous matrix assisted refolding of $\alpha$ lactalbumin by ion exchange chromatography with recycling of aggregates combined with ultradiafiltration. J. Chromatogr. A 2005, 1080, 29-42.

[95] Li, M., Zhang, G., Su, Z., Dual gradient ion-exchange chromatography improved refolding yield of lysozyme. J. Chromatogr. A 2002, 959, 113-120.

[96] Jin, T., Guan, Y.-X., Yao, S.-J., Lin, D.-Q., Cho, M.-G., On-column refolding of recombinant human interferon- $\gamma$ inclusion bodies by expanded bed adsorption chromatography. Biotechnol. Bioeng. 2006, 93, 755-760.

[97] Park, B.-J., Lee, C.-H., Mun, S., Koo, Y.-M., Novel application of simulated moving bed chromatography to protein refolding. Process Biochem. 2006, 41, 1072-1082. 
[98] Park, B.-J., Lee, C.-H., Koo, Y.-M., Development of novel protein refolding using simulated moving bed chromatography. Korean J. Chem. Eng. 2005, 22, 425-432.

[99] Liu, M., Wang, X., Yin, C., Zhang, Z., Lin, Q., Zhen, Y., Huang, H., One-step on-column purification and refolding of a single-chain variable fragment ( $\mathrm{scFv}$ ) antibody against tumour necrosis factor $\alpha$. Biotechnol. Appl. Biochem. 2006, 43, 137-145.

[100] Lemercier, G., Bakalara, N., Santarelli, X., On-column refolding of an insoluble histidine tag recombinant exopolyphosphatase from Trypanosoma brucei overexpressed in Escherichia coli. J. Chromatogr. B 2003, 786, 305-309.

[101] Li, M., Huang, D., On-column refolding purification and characterization of recombinant human interferon- $\lambda 1$ produced in Escherichia coli. Protein Expr. Purif. 2007, 53, 119-123.

[102] Hutchinson, M. H., Chase, H. A., Adsorptive refolding of histidine-tagged glutathione S-transferase using metal affinity chromatography. J. Chromatogr. A 2006, 1128, 125-132.

[103] Li, J.-J., Liu, Y.-D., Wang, F.-W., Ma, G.-H., Su, Z.-G., Hydrophobic interaction chromatography correctly refolding proteins assisted by glycerol and urea gradients. J. Chromatogr. A 2004, 1061, 193199.

[104] Tsumoto, K., Umetsu, M., Yamada, T. I., Misawa, S., Kumagai, I., Immobilized oxidoreductase as an additive for refolding inclusion bodies: Application to antibody fragments. Protein Eng. 2003, 16, 535541.

[105] Mizukami, F., Kiyozumi, Y., Ikeda, T., Kawai, A., Nagase, T., Sakaguchi, K., Chiku, H., Proteinrefolding material. EP1645563 A4 (2006) US2006/0194279 A1 (2006).

[106] Chiku, H., Kawai, A., Ishibashi, T., Takehara, M., Yanai, T., Mizukami, F., Sakaguchi, K., A novel protein refolding method using a zeolite. Anal. Biochem. 2006, 348, 307-314.

[107] Jungbauer, A., Kaar, W., Schlegl, R., Folding and refolding of proteins in chromatographic beds. Curr. Opin. Biotechnol. 2004, 15, 487-494.

[108] Fersht, A. R., Zahn, R., Altamirano, M., Chaparone fragments. WO98024909 (1998).

[109] Altamirano, M. M., Golbik, R., Zahn, R., Buckle, A. M., Fersht, A. R., Refolding chromatography with immobilized mini-chaperones. Proc. Natl. Acad. Sci. USA 1997, 94, 3576-3578.

[110] Dong, X.-Y., Yang, H., Sun, Y., Lysozyme refolding with immobilized GroEL column chromatography. J. Chromatogr. A 2000, 878, 197-204. 